\title{
A BALANCED READING PROGRAMME FOR GRADE ONE AND TWO LEARNERS OF ENGLISH AS A FIRST AND AS ADDITIONAL LANGUAGE
}

\author{
R Wildsmith-Cromarty \& J Gounden \\ University of KwaZulu-Natal, South Africa
}

This study reports on a balanced reading programme (BRP) designed for a multi-cultural, South African classroom at the Foundation Phase. The BRP uses the mother tongue as a valuable resource to access meaning within a supportive learning environment. The main focus of the study is on the achievements of six Zulu children with differing levels of literacy potential after exposure to a year-long balanced approach to literacy. The study also examines parents' views on the BRP and their perceptions of the reading process. Data were drawn from the following sources: teacher observations and interactions with learners; semistructured interviews with parents; analysis of learner assessments and parental questionnaires. It seems that the BRP enhances both the self-confidence and cognitive growth of EAL learners. It also seems that collaborative, interactive learning, extensive independent reading, a language experience approach, home and community support and high teacher expectations of learners, combined with high levels of intrinsic learner motivation can positively impact on EAL learners' academic progress and social growth at school.

\section{INTRODUCTION}

This article describes how a teacher-as-researcher set out to find challenging ways of facilitating the learning of her English as Additional Language (EAL) learners in a class of mostly mother-tongue (L1) English speakers. She interacted with an applied linguist who helped her to link the frontiers of theory with the frontiers of practice. This interaction culminated in the development of a theoretical model - a Balanced Reading Programme (BRP) - for South African learners in multicultural contexts. The core principles of the pedagogic processes were implemented with the same class of learners in both grade one and two. The following questions were used to frame this process:

- How can a monolingual English first language teacher facilitate understanding of an English text when the learners' languages and socio-cultural backgrounds are so diverse?

- Can a balanced approach to literacy instruction, which emphasises both skills and meaningful comprehension, be used to facilitate reading and improve comprehension and enjoyment in a large class of foundation phase learners who come mainly from disadvantaged backgrounds, including African children who are learning through the medium of English? 
- Which teaching techniques and approaches to reading stimulate learner motivation and positive learning attitudes?

Since the abolition of apartheid in South Africa, learners have been able to attend any school of their choice. A large number of African learners have chosen English medium schools because they want to learn English. English-speaking teachers, who are unable to speak African languages, have struggled to teach basic literacy skills to EAL learners. This project was initiated in response to a number of challenges at a multi-cultural school such as significant increases in teacher-pupil ratios, enrolment of EAL learners, an increase in the number of children coming from disadvantaged backgrounds, and teacher frustration at not being able to use the mother tongue of the learners to facilitate learning. In trying to address these issues, the teacher-researcher sought to meet the literacy needs of both the L1 and EAL learners in her class by creating learning experiences that would encourage them to interact with the reading materials in ways that would increase their motivation to read further. More specifically, the study focused on the literacy development of six African children who either had older siblings or lived with other African children attending senior classes in English medium schools. Exposure to English was the main criteria for selection of these learners as a main focus of the study.

The need for a prior knowledge of English on the part of the learners, because of the lack of knowledge of an African language on the part of the teacher, sets this study apart from other South African research into early literacy. The Molteno Project (Gains 2004), originally designed as a breakthrough to literacy in English, was adapted to African Languages because of the realisation that mother tongue enliteration should, ideally, precede enliteration in another language. The two programmes, however, ran concurrently. As in the present study, the Molteno Project uses a balanced approach to all four skills and encourages critical thinking through task-based learning (Gains 2004). It also focuses on small group, interactive learning with the use of pictures to stimulate talk and promote visual literacy, and includes an extended reading programme. Bridge to English then builds on the home language skills developed in Breakthrough to Literacy after the children have already learned to read. The difference here is that the teachers are African language speakers trained in the teaching of early literacy.

A second project (Project for the Study of Alternative Education in South Africa - PRAESA) investigating the teaching of early literacy to South African children, is Bloch's $(1999 ; 2002)$ research into biliteracy development within a multilingual framework. In this respect, it shares similarities with the present study, as it takes a 'child-centred' approach which encourages children to share their prior knowledge of literacy practices learned outside of school. From the outset, two languages (isiXhosa and English) are used simultaneously to teach children to read and write (Bloch 2002). The present study, however, limits the use of the L1 to a supportive role only, as the teacher is not a mother tongue African language speaker.

Based on findings from a Family Literacy Project begun in 2000 in rural KwaZulu-Natal, Ntuli and Pretorius (2005) report that storybook reading to pre-school children had positive effects on their language, literacy and discourse development. Although storybook reading is also the focus of the present study, the contexts and grade levels are different. The Family Literacy Project was not carried out in multilingual settings, as in the present study, but with children in predominantly isiZulu-speaking areas. Furthermore, the focus was on developing 
literacy in the mother tongue through stories, whereas, in the present study, the focus is on the use of the L1 as a scaffold for comprehending English texts.

\section{THEORETICAL PRINCIPLES UNDERLYING THE BRP}

The BRP is underpinned by theoretical principles drawn from theories of language learning, literacy and reading. It draws together central theoretical concerns such as the need for cognitive challenge (Vygotsky, 1978; Cummins \& Swain,1986) and additive bilingualism (Luckett,1993), by using the language of the learners to facilitate an interactive approach to reading. It is based on a theory of literacy as a set of social practices (Chall 2000; Street 1995; Heath 1983), and it retains aspects of traditional reading pedagogies, such as phonics, as part of 'skills empowerment' (Savage 2001).

\section{Language learning theories}

In keeping with the emphasis on using oral language to facilitate understanding of the written word, the BRP draws on language learning theories that embed learning and teaching practices within an interactive learning context, i.e. Communicative Language Teaching, Whole language, Socio-cultural and Socio-cognitive approaches. These approaches facilitate the development of communicative competence so that the learners may interact with their peers in carrying out tasks and activities that would further develop these competencies (Gibbons 1993). The Whole Language approach is based on similar principles, with language learning regarded as a holistic activity in context (Weaver 1994). Drawing on the notion of multimodality (Kress 1997), the BRP uses trans-mediation from one system to another in order to create multiple associations with the learning materials, such as drawing pictures of characters or events in a story; listening to a story on tape or to a dialogue between two of the characters in the home language, or telling the story in one's own language as a prelude to listening to it in English; playing the role of one of the characters in a dramatic performance and, finally, writing a summary of a story. By encouraging the use of the home language to access meaning, the BRP allows the content of literary texts to be first understood in the home language before introducing them in English. This practice complies with the principle of additive bilingualism, as it introduces and validates the use of an additional language into the classroom to which all learners are exposed.

Socio-cultural and socio-cognitive approaches both draw on the work of Vygotsky (1978; 1986) with regard to his recognition and integration of the learners' own cultural funds of knowledge into new learning, and his theory of the zone of proximal development (Hiebert \& Pearson 2000). The principle underlying a socio-cultural approach is that schools are only effective as learning institutions if they see diversity, not as a problem, but as a resource. By drawing on their own prior experience, knowledge and language, learners are able to make links to literary texts presented in class through prior discussion of the content as well as retelling the English version of the story in their own languages. Socio-cognitive approaches are based on the principle that cognitive development is stimulated by a language-rich environment which scaffolds learners in their attempts to understand English texts, and mediates their learning (Chall 2000). Engaging in pair work and peer-teaching activities such as re-arranging story cards about the main events of a story in chronological sequence; matching parts of sentences in order to complete the story; matching sentences from two columns in order to tell the story; drawing and explaining to their peers the main events in the story; designing a book cover for the story in order to attract other readers to the book, and completing story frameworks in order to develop expressive writing skills, requires the 
learners to set goals, organise information, choose strategies and assess the final results of their efforts (Turner \& Paris 1995). Such activities extend the children's learning during the reading process, helping them to become independent problem-solvers. In addition, mediation was provided through the support of 'reading moms'; by older children in the cross-age tutoring project and by the home support programme for parents, in order to reinforce their children's reading experiences. Further scaffolding was provided by the teacher who modelled writing skills using a language-experience approach (Gounden 2003).

\section{Literacy theories}

Gee (1986) argues that school language and literacy acquisition are forms of socialisation into mainstream ways of using speech and print which can seriously conflict with the learners' own primary socialisation, especially if their everyday language use is not the same as the functions and forms of language used in school (Heath, 1983). Furthermore, beliefs about the nature of literacy will influence literacy instruction in the classroom. Street (1995) distinguishes two broad perspectives on literacy: the autonomous model, a narrow view of literacy which emphasises technical skills and promotes 'recognition literacy', and the ideological model, which views literacy as a set of social practices, thus promoting 'reflection literacy' (Hasan \& Williams, 1996). If non-mainstream children are taught only recognition literacy, they will learn to read by 'cracking the code', but will lack the skills to reflect on what they read. If, however, they can bring their own literacy practices through the medium of the L1 into the classroom, such as praise poems, stories, cultural songs and hymns, this will facilitate understanding and develop the potential for comparing different literacy practices (Dombey, 1996). The BRP draws on all of the above - the traditional approach, emergent literacy theory and literacy as social practice - in order to create a 'balanced' experience of reading.

Although more recent theories stress the importance of meaningful reading (Carrell, Devine \& Eskey, 1988), they tend to ignore the needs of 'at-risk' learners who still need direct skill tutoring (Adams, 1990). In this regard the traditional approach has much to offer in terms of utilising teaching methods which promote automatic skill mastery through the principle of over-learning. Children coming from literacy-sparse environments need direct teaching of basic reading concepts e.g. sounds of the alphabet, shapes of letters and phonemic awareness which are crucial elements in the 'learning to read' process. It cannot be assumed that these learners are emerging readers and writers prior to formal schooling

The BRP focuses on the use of three cueing systems (semantic-development of vocabulary; syntactic-use of grammatical knowledge; phonological-graphonic-sound to symbol) in decoding a text, whilst simultaneously building up the learners' background and conceptual knowledge in order to access meaning. The underlying principles of emergent literacy theory further provide a platform for some useful pedagogic practices in the BRP e.g. modelling the processes of reading and writing, shared book reading, encouraging children to read and write at home, and celebrating children's progress towards more conventional forms of reading and writing. The shared book experience using the 'Big Book' (see Cunningham et al 1995 for a description of this type of reading) is especially valuable for promoting timed readings of 'chunked' meaningful language, whilst simultaneously building bridges between the L1 and L2 through use of the L1. 


\section{Reading theories}

Running parallel to the language learning and literacy theories mentioned above, reading instruction in schools followed either a traditional, teacher-driven approach, or a 'natural', learner-driven one (Chall, 2000). The former emphasises the technical, lower-order skills for decoding text (sound-symbol correspondence; phonic instruction etc.) while the latter emphasises the need for whole, real and relevant language for beginner readers. The BRP used the traditional approach to build up the learners' word recognition skills through the use of flashcards and contextual cues, and by guiding them through the various reading phases (awareness phase; pre-alphabetic phase; partial alphabetic phase; full alphabetical phase and consolidated alphabetical phase) in order to help them develop efficient word recognition abilities (Stahl, 1998; Ehri, 1995).

The teaching of phonics moved away from excessive monotonous drilling and focused on teaching phonics in meaningful contexts, using a whole- part- whole instructional framework which integrated learning to read with real reading (Trachtenburg, 1990). Periodic drilling of word families by sounding and blending was used to facilitate the acquisition of a basic reading vocabulary. By developing musical tunes (auditory modality), children learnt how to sound out their blends. Whenever they came across unknown words, they were encouraged to use their fingers to block letters (kinesthetic modality), and then sound out and identify phonic blends and patterns in words. The BRP motivated learners to become strategic and independent in their use of phonics as the children created words and sentences with the phonic blends. These sentences were condensed into a phonic booklet which children took home for reading. The phonic booklets gave learners opportunities to extend their vocabulary, improve word recognition and increase comprehension levels.

The BRP also uses an interactive model of reading, which makes use of approaches which are simultaneously top-down (emphasising the meanings that readers bring to the text), and bottom-up (emphasising decoding skills) (Carrell et al., 1988). Thus, in grade one, the teacher commenced with four teacher-written literature stories which had a sense of 'storyness' that generated discussion on fundamental human issues (Collie and Slater, 1987). This practice was based on the principle that young readers need to be introduced to texts that are both predictable in their language use and structure, and of real interest to them. This 'natural' approach also involved guided reading sessions where learners were helped to internalise the structure of stories through various oral activities (Turner \& Paris 1995). Boyle and Peregoy (1990) argue that in order for children to gain meaning from print, teachers need to make full use of the children's talk during reading - using their spoken language to build bridges between the child's culture and the imaginative world of the reading text. For example, the children were asked to role-play some of the characters as they went along in the story. In this way, learning to read and reading for pleasure became collaborative activities. The teacher preferred her own 'stories' to basals, because the stories in these books are often experienced as 'puzzles' that youngsters have to piece together, with an overemphasis on phonics. However, she did use the basals for individual practice in class, and also for the home support programme as parents preferred the increased structure that they offered.

An independent reading programme was also used to naturally improve the quality of language use, language knowledge and general academic performance (Krashen, 1993; Nation, 2001). Learners of different proficiency levels learnt at their own pace and exercised their freedom to choose reading books which captured their interests. This free reading project stimulated reading motivation because the children were no longer trapped in an inflexible 
class programme. Immediately after the first break, the children engaged in fifteen minutes of silent reading of high interest storybooks. Sometimes they were allowed to take their library books home. After reading their books, the children entered the title into their reading logs and completed story frameworks asking for the parts they enjoyed the most and least in the story. The teacher set reading targets every fortnight and when the children accomplished their goals they received tokens to celebrate their progress. The BRP gradually made children take responsibility for their own learning as they began to internalise their goals and purposes for reading.

In sum, the BRP attempts to keep the following in balance:

$>$ Listening, speaking, reading and writing skills

$>$ Principles of natural language with principles of direct teaching

$>$ A meaning-emphasis approach to reading with a code-emphasis approach

$>$ Home support with school support programmes

$>$ Home knowledge with school knowledge

$>$ Home language with the instructional language at school

$>$ Individual learning with collaborative learning

$>$ Literature-based stories with graded basal readers

The main aim of the programme was to facilitate literacy in English, drawing on the above principles in order to create a balance between traditional and more innovative and recent pedagogic and reading approaches. It was felt that these particular children (including the EAL learners), who did not have the benefit of a reading-rich environment at home, would benefit more from a balanced programme which began with the more structured traditional methods. By using the home language as a scaffold, it attempted to draw in the EAL learners in the classroom, whilst at the same time exposing the other learners to the African language in a natural and meaningful way. Thus, although most of the reading activities such as sentence-matching, creating phonic booklets, etc, were carried out in the classroom through English, the teacher-written stories were first translated into isiZulu and pre-recorded by an isiZulu speaker who told the story with fluency and expression. This helped the EAL learners to think and build 'schemas' in their home language. They then used this knowledge as a basis for role-play scenarios in isiZulu before listening to the teacher reading the story in English from the 'Big Book'. The activities included in the home support programme were intended to be carried out in English, although the EAL learners in particular were encouraged to practice telling the stories to their caretakers at home in the home language first, before reading them in English. They were also encouraged to tap into their own 'cultural funds of knowledge' at home by asking their parents and other family members for praise poems and other stories which they could then share with their teacher and peers in class.

\section{RESEARCH METHODS AND DATA COLLECTION}

\section{Participants}

The participants in this longitudinal study were grade one pupils attending a multicultural urban school in KwaZulu-Natal, and their caretakers. These pupils continued as participants during their grade two year. The context was a state, ex-House of Delegates school in Pietermaritzburg, KwaZulu-Natal. There were 50 pupils in the class of which 33 were EL1 Indian pupils, and 17 EAL African pupils. Questionnaire results revealed that these learners mostly came from working class backgrounds where a culture of reading had not been 
strongly established. Although all learners were exposed to the BRP, the progress of six of the African learners was specifically tracked because they had all attended pre-school and could speak some English on entry to the school. The learners included three boys and three girls all of whom turned eight in their grade one year. Some proficiency in English was necessary for this study as the monolingual teacher needed to interact quite closely with them in order to facilitate their literacy development. It was also important for the children to be able to interact with someone at home who could understand and read some English in order to implement the home support programme. According to the results of the questionnaire, most parents were working, but they agreed to put aside time in the evenings in order to monitor their children's reading practice. The parents' English proficiency varied from family to family but all of them had sufficient English in order to help their children. For most parents, this was their first exposure to a multicultural, English-medium primary school.

\section{Data Collection}

The research approach in this study was ethnographic and interpretive, as it entailed the collection of qualitative data over a two-year period (Grades 1 and 2) during which the teacher was researching her own pedagogy. Data were collected by means of questionnaires, semi-structured interviews, informal conversations with learners, samples of the learners' written work, formal reading assessments and continuous observation with field notes.

Parental questionnaires were used in the early phases of the research in order to assess parents' perceptions and knowledge about the teaching of reading, including the role of comprehension, code-breaking and typical difficulties with learning to read (Appendix 1). The assumption was that parental beliefs about reading could influence the reading performance of their children. This was followed by semi-structured interviews with parents in order to monitor their children's progress in the home support programme. These interviews took place at least twice a month. A second interview with a questionnaire was then administered at the end of the reading programme to gauge perceptions of the BRP (Gounden 2003). The information gained from this instrument revealed the extent to which the home support programme had contributed to success in reading (Appendix 1). Throughout the implementation of the BRP, open-ended questions were used during informal conversations with the children whilst interacting with them in class in order to assess the effectiveness of the programme (Appendix 1). Data produced during these interviews, together with informal conversations with the learners and their written work during reading activities, helped build valuable literate life histories of each of the children in the case study (Appendix 2), which, in turn, created awareness of the cultural richness and learning potential of these learners. At grade 2 level, however, additional data were produced by more formal reading assessments measuring comprehension and fluency (Gounden 2003).

The principal research method used to both implement, and assess the BRP, however, was observation with field notes. The teacher-researcher worked closely with the children, trying out different reading methods and techniques, and monitoring their progress. The various techniques were drawn from different theoretical perspectives on the teaching of early literacy in an attempt to achieve a 'balanced' reading programme (Spiegel 1992; Savage 2001). The results of these efforts were captured in the form of narratives as journal entries labelled 'process notes', created from daily field notes regarding the reading behaviours of the six EAL children during various learning activities. The teacher's journal allowed the researcher to reflect on and record the psychological, social and affective factors involved in teaching learners to read - something not readily retrievable through experiments (McDonough \& 
McDonough 1997; Neuman 2000) - and to reflect on the learners' responses to the particular activities offered in the BRP. At this early stage, assessment of learners' oral and written language development is best done through observational procedures and the collection of performance samples (Hiebert \& Pearson 2000). Evaluation was thus carried out on a continuous basis in order to monitor the learners' progress. This included the following:

- Examination of reading logs every fortnight

- Word recognition skills

- Performance on reading tasks on a daily basis

- Ability to construct meaningful sentences based on personal experience or on selected topics

- Ability to report on what they had read

- Reading speed and spelling ability

- Learning motivation and enthusiasm

- Pupil interaction during group reading sessions

\section{RESEARCH FINDINGS}

The data were analysed according to themes, patterns and relationships which emerged from the various research instruments and were supported by the teacher's journal entries. The field notes were analysed repeatedly for recurrent themes which would reveal how the learners were responding to the BRP. The following themes emerged: motivation, communicative competence, collaborative learning, writing competence and word recognition.

\section{Motivation}

The six EAL children showed clear signs of becoming motivated learners as their reading experiences enhanced their self confidence. As they began to experience the joys and rewards of reading, extrinsic motivation transformed itself into intrinsic motivation. The children set targets as to how many books they wanted to read for the week and completed their basal readers with eagerness.

Journal entry: October 20, 2001. I began the independent reading programme two months ago and am amazed at the children's reading progress. It is pleasing to see the children choosing books that are slightly beyond their current level of reading competence.

Journal entry: March 20, 2002. At the beginning of grade two, in 2002, I noticed increased reading levels amongst the six EAL children. I think the independent, extensive reading of library books as well as the reading of stories has increased the vocabulary and reading rate of both $\mathrm{L} 1$ and EAL learners because now they are finishing their basals with eagerness. Often I hear the children demanding another book "We have finished reading the book!" "When are you going to give us another book?" and "But you promised to give us a new book today!"

\section{Communicative competence}

With increased exposure to the BRP, the EAL learners were gaining confidence in pursuing a conversation with their English speaking counterparts. They could hold longer, more extended 
conversations and were able to select appropriate words and phrases in order to sustain them. During post-reading activities, children eagerly prepared props. They made masks, puppets and brought appropriate clothing from home for their dramatic performances. Reading to them was not confined to the text; it gave them opportunities to extend their creative abilities and talents, which added texture to their holistic literate development.

Journal entry: June 19, 2002. Today I was impressed by the way two of the girls participated in drama. Sinesipho (cruel stepmother) became bold, brave and aggressive, thus adding vigour to her dialogue. Nomalisa (Cinderella), remained submissive and spoke softly and lovingly, with grace. Her emotional outbursts had an empathetic effect on the other children in the class. When these girls took the platform, the class was absolutely silent, giving them their undivided attention. Although Sinesipho struggled to keep pace with her reading ability group, she had an abundance of talent and poise. After this drama session, it became apparent that African children come from a rich oral culture. Both these girls could narrate the story of Cinderella with fluency and accuracy in both English and isiZulu.

\section{Collaborative learning}

During pair and group work, the children were sharing their cultural knowledge. Through the literature discussions, these children spoke about their religious practices, as well as their appreciation of how other cultures differed from their own. By normalising diversity and enriching the cultural experiences of all learners, the BRP sought to contribute to life-long learning.

A further form of collaborative learning was the cross-age tutoring project where grade three pupils read with the grade two pupils. This further enhanced the literacy progress of struggling readers.

Journal entry: August 5, 2002. I think the children appreciated the older children coming to assist them during the breaks. The older children modelled good reading as the younger children listened attentively. The children themselves set targets for the week and negotiated how they would accomplish their goals. The programme ran for 15 minutes on three days of the week. The children were very disciplined and made maximum use of every minute. Some children just listened to their partners reading to them while others decided to speak about the story and read along with their partners.

\section{Writing competence}

Generative moments signalled children's movement toward more mature writing competence. As the six children's reading competence improved, so did their writing competence, as they were becoming more open to writing conventions e.g. punctuation. They were becoming more spontaneous in expressing their ideas possibly because the emphasis had shifted from correct spelling and grammar. Writing motivation increased as children were given autonomy over the writing process as they chose their own topics for free writing (Hodson and Jones, 2001).

Journal entry: June 14, 2002. I did find reading much easier to teach than writing. I struggled with writing because I found it very difficult to correct mistakes and give remedial assistance to so many pupils. Therefore, on some days, I presented modelled writing on selected topics to further enhance reading and writing skills. Initially, the 
children took a long time to think about and express their ideas. I had a fairly good idea of each child's writing competence so I decided to set limits for them. I put a dot in the child's book and encouraged him/her to try and write till that point. As time progressed, I raised the limits and surprisingly enough, the children stretched their limits as well. I also noticed they remained silent for a long period of time when they were writing. They were pausing, thinking and reading what they wrote. They often engaged in self correction.

Journal entry: August 15, 2002. "Inventive spelling" was a valuable resource to improve writing competence. Due to the large numbers in my class it was impossible for me to spell all the words the different children needed in order to complete their written tasks. So I decided to show them how to do "inventive spelling" where they sounded out the words and wrote them down. Whenever I gave children a piece of written work, they would ask me whether they should use "invented spelling or dictionary spelling". I noticed the smiles on their faces when I said "inventive spelling". By using "inventive spelling" the children could concentrate on putting their thoughts down on paper with confidence and independence.

\section{Word Recognition}

The six children were deciphering unknown words by applying strategies they had been exposed to in the BRP. They even challenged their peers at word recognition. Towards the latter part of the programme, the frequency with which these children came to the teacher for help in word recognition decreased. Whenever the teacher wrote sentences on the board, the children would immediately engage in using contextual clues, sounding out the words, blending and looking for patterns as they tried to decode and encode unknown words. Whenever children came across words with a particular blend in their readers, they added these words to the appropriate chart on the word wall.

Journal entry: November 9, 2001. Today I watched Sipho and Andiswa revising their flashwords in the carpet area. Sipho emptied his flashwords from his plastic container. He picked up each card and read the words loudly. He seemed quite confident as he could recognise all 30 words. Andiswa, on the other hand, recognised 25 words. He then went to the word wall and started to read the story and tried to locate the unknown words in it. Surprisingly enough, he was able to read and work out at least three of the words on his own by using contextual clues.

Journal entry: August 5, 2002. Today Freddy really enjoyed putting up words on the "word wall". He found two words with the /l/ sound. I had 'table' and 'apple' on the chart. Freddy came across the words 'trouble' in his reader, and 'marble', in his dictionary, and added them to the chart.

Journal entry: August 15, 2002. I told Sipho to read the instruction from the chalkboard. He spoke clearly and loudly, and managed to decipher the word 'experience'. Furthermore, he was asked to read and explain the English instruction on the board in isiZulu and in English. He executed his task with commitment and confidence. 


\section{VERBAL REPORTS OF THE PARENTS AND LEARNERS}

During the implementation of the BRP, the teacher-researcher captured parents' thoughts in the monthly semi-structured interviews (Gounden 2003). These comments reflect the parents' satisfaction with their children's reading progress as a result of the home support reading programme. From the comments, it is evident that the BRP made parents aware of their children's abilities and capabilities. The BRP also gave parents opportunities to participate actively in their children's education. The comments made by the learners themselves acknowledge that the BRP had stimulated their multiple intelligences, increased their reading motivation and created spaces for them to celebrate their literacy progress.

Nomalisa developed quick thinking skills and was capable of making appropriate responses during the drama sessions, both in Zulu and in English. She was able to apply grammatical rules in context and was capable of writing longer sentences using conjunctions to make complex sentences. She read avidly and retold the stories clearly and concisely. She was quick to get the gist of a story because she was able to increase the pace of reading by applying skimming and scanning skills efficiently during guided reading sessions.

Nomalisa: After I finished reading the story, I like to tell my friend about what I know because I like to tell the story.

Mother: I am happy about Nomalisa's reading progress because now she can read fast without stopping, and she knows the big words.

Diduzi_was an attentive listener who finished her basal readers with speed. At times she became impatient and demanded that the teacher listen to her group read so that they could move on to the next book. She thoroughly enjoyed independent reading sessions because she could choose the books that she wanted to read.

Diduzi: I like when you tell us to draw pictures in our books because we can use our crayons and show how the story goes.

Mother: I see she can read all her books she brings home and she even teaches her big sister all the books you give her.

Sinesipho. The "Big Book" approach boosted her reading confidence in grade one. In grade two, during the guided reading sessions, Sinesipho did translations from English to isiZulu. She was a real "live wire" during the literature discussions because she was so skilful at making the connections between knowledge gained in the classroom and knowledge gained outside the classroom.

Sinesipho: I like when you put me to read with someone because that person he knows to read nice and I too gonna read like him.

Mother: I think Sinesipho is getting good now, because Sinesipho is trying and I teach her everyday and, even if I'm cooking, she comes to the kitchen and I try hard and she try hard.

Freddy enjoyed predicting what was going to happen in the story. He made intelligent guesses and was happy when his predictions were correct. He loved looking at pictures and talking about them in isiZulu to his Zulu-speaking peers. His reading fluency increased after repetitive reading. 
Freddy: I like the books you put in the library corner because it makes me clever and if I read lot I learn lot.

Mother: I listen to him reading everyday and I know he is getting okay in his reading because he is working very hard, and sometimes I see he finish the book quick.

Sipho's reading fluency improved greatly. He often borrowed library books and finished them overnight. During guided reading sessions, he spoke with courage and determination to put his points across.

Sipho: I like when you show us how to find out how to say a big word. And now I can find the words in the book and write it on the wall.

Mother: I look at Sipho's reading books everyday and sometimes his sister she help him to read so that he can pass good.

Andiswa was a great source of inspiration to other isiZulu speakers, being proud of his language and culture. He enjoyed writing about his own experiences and reading them to his peers. During independent reading sessions, Andiswa was always engrossed in whatever he was reading. Whenever he completed a book he told his friends about it so that they too would be motivated to choose that book the next time.

Andiswa: I like to say the story in Zulu and in English because I know how it happened and I want to show my friends the pictures in the book and see what the people in the book do to make the story.

Mother: Andiswa understands everything in the book.... He is good. He knows it in Zulu and in English.

\section{READING ASSESSMENTS}

During the course of the BRP the learners had been divided into five reading groups reflecting different levels: good, average and weak. In grade one, at the beginning of the research period, four of the six EAL learners were placed in Group 3, and 2 in Group 4. By grade 2, the group 3 learners had advanced to group 1, and the group 4 learners had advanced to group 2. Towards the end of the research period (end of grade 2), these learners also participated in a reading assessment that contained similar reading activities to those to which the children had been exposed in the BRP (Gounden 2003). Five English stories were used, similar to those that the learners had encountered in the BRP. The learners were assessed on ten aspects of literacy using a Likert rating scale. The learners were familiar with the activities, which were as follows:

- Reading ability and fluency

- Rearranging sentences to show the chronological sequence of a story

- Rearranging words to make meaningful sentences

- Matching parts of sentences

- Retelling a story and drawing pictures to explain the events in the story

- Answering five general questions on the story

- Demonstrating the meaning of selected words from the story

- Identifying words which have selected blends or word patterns in a story

- Giving personal responses to the story

- Word extension 
From an analysis of the learner's scores (100\% for all six learners) it was concluded that the BRP had stimulated their ability to focus on meaning (points 2 - 6) e.g. apply cueing systems simultaneously; chunk meaningful language units to improve reading fluency (understanding of the whole story facilitated reading meaningful phrases with speed), use various learning modalities such as artwork to organise their thoughts and consolidate comprehension of a story, and use a variety of word recognition strategies to identify words with ease e.g. apply phonic skills and use contextual cues. It seemed that having a prior understanding of the story as a whole increased their comprehension levels of the various parts (words, phrases and sentences). The four readers in the 'good' reading group were able to process meaningful chunks of language more rapidly than the weaker readers, thus affording them more time to apply different word recognition strategies to unfamiliar vocabulary. This was helped by the larger amount of extensive reading they engaged in during class. All leaners obtained lower scores on criteria 7 - 10. The 'good' readers scored $80 \%$ on average, and the weaker readers $60 \%$, for demonstrating understanding of vocabulary items appearing in the text; identifying words in the texts with similar patterns or blends; word-formation (extending word roots from the passage to build bigger words by adding suffixes), and relating their own personal experiences to the stories. However, the use of artwork to help recall the story helped the learners organise their thoughts and consolidate comprehension. By engaging these learners in functional reading (discussing the content of the pictures they were drawing), and writing (organising the various events in a story in chronological sequence, and recording their personal responses to the stories), the BRP demanded active engagement from the learners with the text in ways which helped to increase comprehension and consolidate learning.

\section{ANALYSIS OF PARENTAL QUESTIONNAIRES}

Findings revealed that parents of the more able readers came from literate backgrounds and tended to value the more traditional aspects of reading pedagogy, such as the pre-teaching of unknown words (scores for parents of all three levels of readers - good, average and weak were over $70 \%$ for this question); adherence to punctuation conventions (56\% for parents of good readers; $40 \%$ for parents of weak readers); word accuracy and phonics (60\% for parents of good readers; $20 \%$ for parents of weak readers) compared to the parents of less able learners who did not value these reading skills so highly. All parents disagreed with the statements that learners should be encouraged to guess at unfamiliar vocabulary $(54 \%$ as opposed to $22 \%$ who agreed with the statement); that if learners use a similar word (eg. house for home) thus demonstrating an understanding of the concept itself, it should be left uncorrected (54\% disagreed as opposed to $30 \%$ who agreed) and that it is not necessary to introduce new words before they appear in the reading text (66\% disagreed whereas $22 \%$ agreed). These results reveal that, in general, parents valued bottom-up processing skills as a vital component of the learning-to-read process, whilst minimising the value of guessing and word substitution which derive from a whole language approach. Nevertheless, there was an interesting distinction between the beliefs of the Indian (L1) and African (EAL) parents regarding a focus on meaning in their children's initial encounters with print. The African parents agreed with the statement $(47 \%)$ whereas Indian parents disagreed (58\%). Perhaps the parents of the L1 learners took for granted that comprehension would take place automatically once rapid and fluent decoding was established (Bond and Dykstra, 1967).

The findings of the questionnaire that canvassed parental perceptions of the BRP revealed that they generally favoured a home support reading programme that was more structured in terms of the reading materials used (i.e. basals) and the scaffolds provided in the form of practice 
activities. African parents welcomed opportunities and guidance from school to help their children make rapid progress in literacy. However, parents had mixed reactions to the mother tongue instruction issue. Whilst some parents saw the value of promoting the mother tongue, others saw it as a barrier to learning. They preferred the straight-for-English model which promises competence in English for their children. They did not perceive that the BRP was addressing the development of competence in both languages.

\section{CONCLUSION}

Both EAL and L1 learners flourish in a print rich environment where they are given opportunities to read extensively. Extensive reading in a second language, accompanied by positive attitudes and strong motivation can transform learners into successful readers (Day and Bamford, 1988). It also helps move them towards independence.

Encouraging African learners to use their native language to understand story content and respond to literature discussions enhances their self-confidence and instils pride in their culture and language. In addition the non-Zulu children gain exposure to multiculturalism. By utilising their multiple intelligences through various learning modalities and holistic learning experiences, the BRP sought to bring alive their talents and capabilities for life long learning.

Collaborative learning experiences allow EAL learners to interact with L1 learners in functional ways. This helps develop communicative competence which automatically feeds into reading comprehension. Interactive story reading promotes the exchange of cultural knowledge amongst the classroom community in a multicultural context.

Parents of EAL learners respond well to a tightly structured home support programme which helps them make a contribution to their children's literate development. Interactive story reading in the home environment promotes confidence and the cultural understanding and interpretation of texts which the learners can then introduce to other learners.

The teacher's use of writing frameworks to structure the children's writing attempts stimulated the thinking skills and writing confidence of both EAL and L1 learners. In addition, the story frameworks encouraged the learners to respond to and reflect on the stories.

The research reported on in this paper proceeded on the assumption that, although the language issue puts EAL learners at a potential disadvantage in an English-medium school, they can continue to show the same capacity for learning as other children, provided they receive appropriate intervention and high expectations from their teacher (Gibbons, 1993). Teachers at the Foundation Phase would do well to be proactive in providing early intervention and support in recognition of the children's learning and literacy difficulties that are language-related. One way of providing this support is through the recognition and use of the children's home language. This provides a scaffold for the EAL learners, whilst simultaneously enriching the learning experiences of all the learners in the classroom. 


\section{REFERENCES}

ADAMS, MJ. 1990. Beginning to read: Thinking and learning about print. Cambridge, Mass: MIT Press.

BLOCH, C. 1999 Literacy in the early years: teaching and learning in multilingual early childhood classrooms. International Journal of Early Years Education, 7(1): 39-59.

BLOCH, C. 2002. A case study of Xhosa and English biliteracy in the foundation phase versus English as medium of instruction. Perspectives in Education. 20(1): 65-78.

BOND, GL \& R DYKSTRA. 1967. The co-operative research programme in first-grade reading instruction. Reading Research Quarterly, 2(1): 5-142.

BOYLE, OF \& SF PEREGOY. 1990. Literacy scaffolds: Strategies for first and second language readers and writers. The Reading Teacher, 44(3): 194-200.

CARRELL, PL, J DEVINE \& DE ESKEY. 1988. Interactive approaches to second language reading. Cambridge: Cambridge University Press.

CHALL, JS. 2000. The academic achievement challenge: What really works in the classroom? New York: Guilford.

COLLIE, J \& D SLATER. 1987. Literature in the language classroom: A resource book of ideas and activities. Cambridge: Cambridge University Press.

CUMMINS, J \& M SWAIN. 1986. Bilingualism in education: Aspects of theory, research and practice. London: Longman.

CUNNINGHAM, PM \& DW MOORE. 1995. Reading and writing in elementary classrooms: Strategies and observations. $\left(3^{\text {rd }}\right.$ Ed). White Plains, NY:Longman.

DAY, RR \& J BAMFORD. 1988. Extensive reading in the second language classroom. Cambridge: Cambridge University Press.

DOMBEY, H. 1996. Enlarging the 'ways of taking' from literary texts. Mode-switching in the primary classroom. In Baker, D, J Clay \& C Fox (eds), Challenging ways of knowing in English, Maths \& Science. London: The Falmer Press. 62-70.

EHRI, LC. 1995. Phases of development in learning to read words by sight. Journal of Research in Reading, 18: 116-125.

GAINS, P 2004. The Molteno Project. Paper presented at the first RASA conference, Cape Town, November 2004.

GEE, JP. 1986. Orality \& literacy: From the savage mind to ways with words. TESOL Quarterly, 20(4): 719-743.

GIBBONS, PC. 1993. Learning to learn in a second language. Portsmouth, Hants: Heinemann. 
GOUNDEN, J. 2003. A balanced reading approach for grade one and two English L1 and EAL learners. Unpublished MA Dissertation, University of KwaZulu-Natal.

HASAN, R \& G WILLIAMS. 1996. Literacy in society. London: Longman.

HEATH, BRICE S. 1983. Ways with words: Language, life and work in communities and classrooms. Cambridge: Cambridge University Press.

HIEBERT, EH \& PD PEARSON. 2000 Building the past, bridging to the future: A research agenda for the centre for the improvement of early reading achievement. Journal of Educational research, 93(3): 133-145.

HODSON, P \& D JONES. 2001. Teaching children to write: The process approach to writing for literacy. London: David Fulton Publishers.

KRASHEN, S. 1993. The power of reading. Englewood, Cliffs: Libraries Unlimited.

KRESS, G. 1997. Before writing: Rethinking paths to literacy. London: Routledge.

LUCKETT, K. 1995. National additive bilingualism: Towards a language plan for South African education. In Heugh, K, A Siegruhn \& P Plüddemann 1995 Multilingual education for South Africa. Johannesburg: Heinemann. 73-78.

MCDONOUGH, J \& S MCDONOUGH. 1997. Research methods for English teachers New York: St Martin's Press.

NATION, ISP. 2001. Learning vocabulary in another language. Cambridge: Cambridge University Press.

NEUMAN, WL. 2000. Social research methods: Qualitative and quantitative approaches $\left(4^{\text {th }}\right.$ edition). Cambridge: Cambridge University Press.

SAVAGE, J. 2001 Sound it out! Phonics in a balanced reading programme. Boston, Mass.:McGraw-Hill.

SPIEGEL, DL. 1992 Blending whole language and direct instruction. The Reading Teacher, 46(1): 38-44.

STAHL, SA. 1998. Understanding shifts in reading and its instruction. Peabody Journal of Education, 73: 31-67.

STREET, B. 1995. Social literacies. London: Longman.

TRACHTENBURG, P. 1990 Using children's literature to enhance phonic instruction. The Reading Teacher, 43(9): 648-653.

TURNER, J \& SG PARIS. 1995. How literacy tasks influence children's motivation for literacy. The Reading Teacher, 48(8): 662-675. 
WEAVER, C 1994. Reading processes and practice from sociolinguistics to whole language. $\left(2^{\text {nd }} E d\right)$. Portsmouth, NH:Heinemann.

VYGOTSKY, LS. 1978 Mind in society: The development of higher psychological processes. (Edited by M Cole). Cambridge, Mass: Harvard University Press.

VYGOTSKY, LS. 1986 Thought and language (Edited \& Translated by A Kozulin). Cambridge, Mass: Harvard University Press.

\section{Bibliographic Note}

Rosemary Wildsmith-Cromarty is Professor of Applied Language Studies at the University of KwaZulu-Natal. Her e-mail address is: wildsmithr@ukzn.ac.za. Rogini Gounden is a Foundation Phase teacher at a multicultural school in Pietermaritzburg. 


\section{APPENDIX 1}

\section{SEMI-STRUCTURED INTERVIEWS}

\section{Parents of the six African children}

1. Can you tell me about your family?

2. Where was " $\mathrm{X}$ " born? Can you tell me about his/her early life before formal schooling?

3. Can you tell me about "X's" first experience with books or writing materials?

4. Can you tell me how and when "X" first learnt to speak English?

5. Who helped " $\mathrm{X}$ " to read and write, and how did they do this?

6. Can you comment on your child's reading progress so far?

7. Is there anything you would like to discuss further about " $X$ ' $s$ " reading progress?

8. Why do you think " $X$ " is coping/not coping with his/her school work?

9. Are you confused about anything in the flip file? Do you want me to explain it?

10. Does your child enjoy/not enjoy reading? Why/Why not?

\section{Informal conversations with the six children}

1. Can you tell me about your family and early life before you came to this school?

2. Did anyone teach you to read and write before you came to pre-school? Tell me about it.

3. Did you learn anything new today? Tell me about it.

4. I saw you reading that book today. Why did you choose it?

5. Did you find that reading activity useful/not useful? Why/why not?

6. Can you explain what you just drew?

7. Did you enjoy/not enjoy working with your partner? Why/why not?

8. Are you happy/not happy with the way you now read? Why/why not?

9. Has anybody at home listened to you reading recently and how did they respond to you?

10. Do you like reading alone or when we do group discussion and activities? Why/why not? 


\section{APPENDIX 2}

\section{FREDDY'S LITERATE LIFE HISTORY}

Freddy is the fourth son in the family. He was born in Northdale. In his early years, he did not come into contact with reading books. However his mother used to tell him stories in isiZulu. Whenever his mother told him the story of "Imotho ehlaza" Freddy would take a plastic plate from the kitchen and pretend to drive a car. He would also make sounds to indicate the speed at which the car was travelling. When he was a little older, he joined his twin brothers in outdoor sport. It was here that he came into contact with his Indian neighbours. Soon he started learning to pronounce English words. He played soccer, cricket and hide-and-seek. When Freddy turned four he attended the nearby crèche. Here there were many African children and a few Indian children. He had an Indian teacher. It was here that he learnt his first nursery rhyme "Jack and Jill". His mother bought him colouring books. Whenever Freddy found a piece of paper, he would scribble and make patterns, and assembled animal puzzles. He also learned to count and identify numbers. He spent two years at this crèche. When he was six, his mother began reading the Bible in isiZulu to him. He also spent a lot of time watching English cartoons. Freddy went to pre-school in an ex-House of Delegates school when he was six. In the same year, his brothers began attending isiZulu classes run by a community member. They used to show him isiZulu words from their lessons. When Freddy began school in grade one, his elder brother used to help him with his reading. He used to 'flash' words to him, and tell him the meanings of the words in isiZulu. Soon the nature of the conversations at home began to change. Whenever Freddy conversed with his brothers, he used both isiZulu and English words to communicate. His mother also played an active role in developing his reading skills. She wrote sentences in English and made him read, and then copy them down. She read with him and to him. 


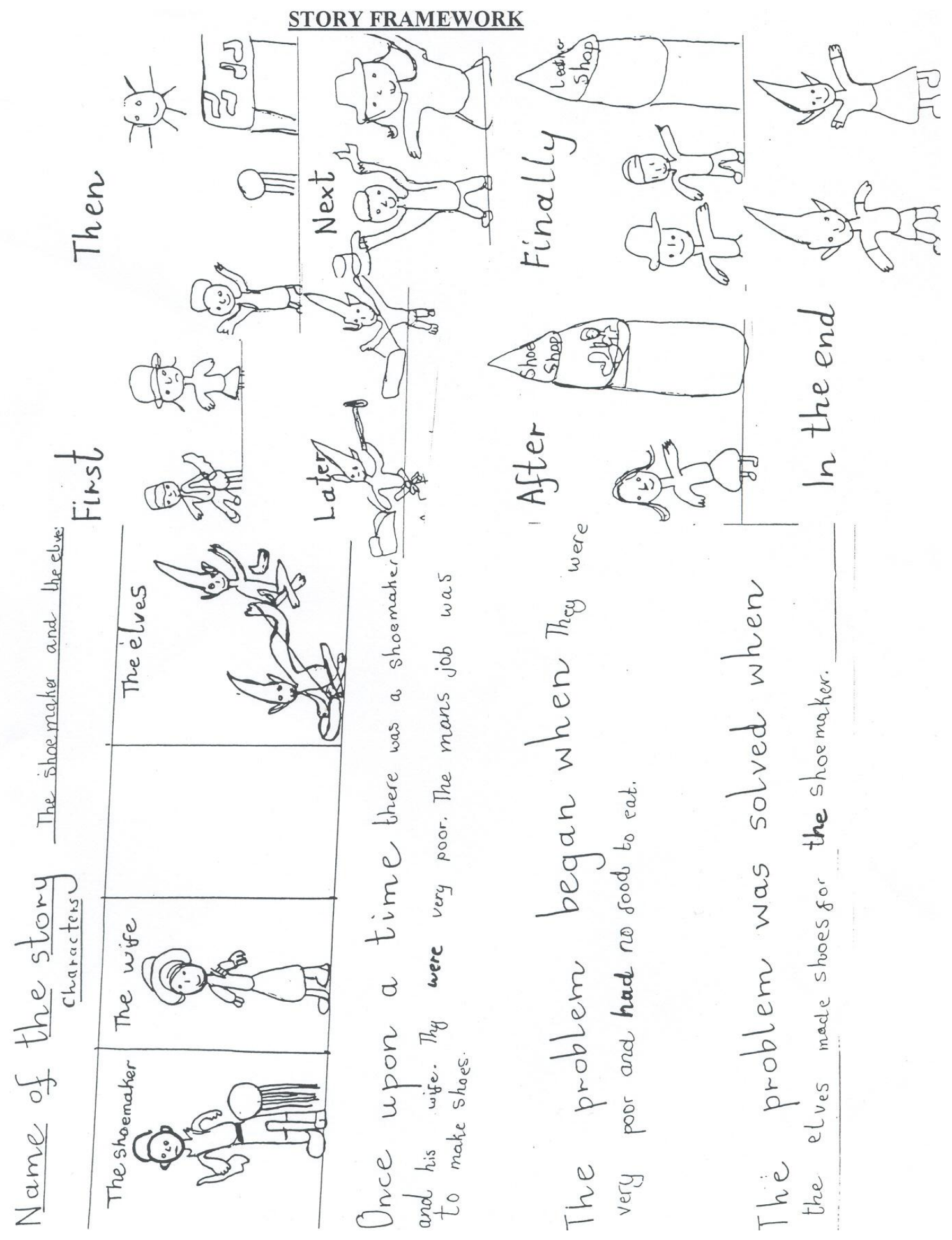




\section{PERSONAL WRITING}
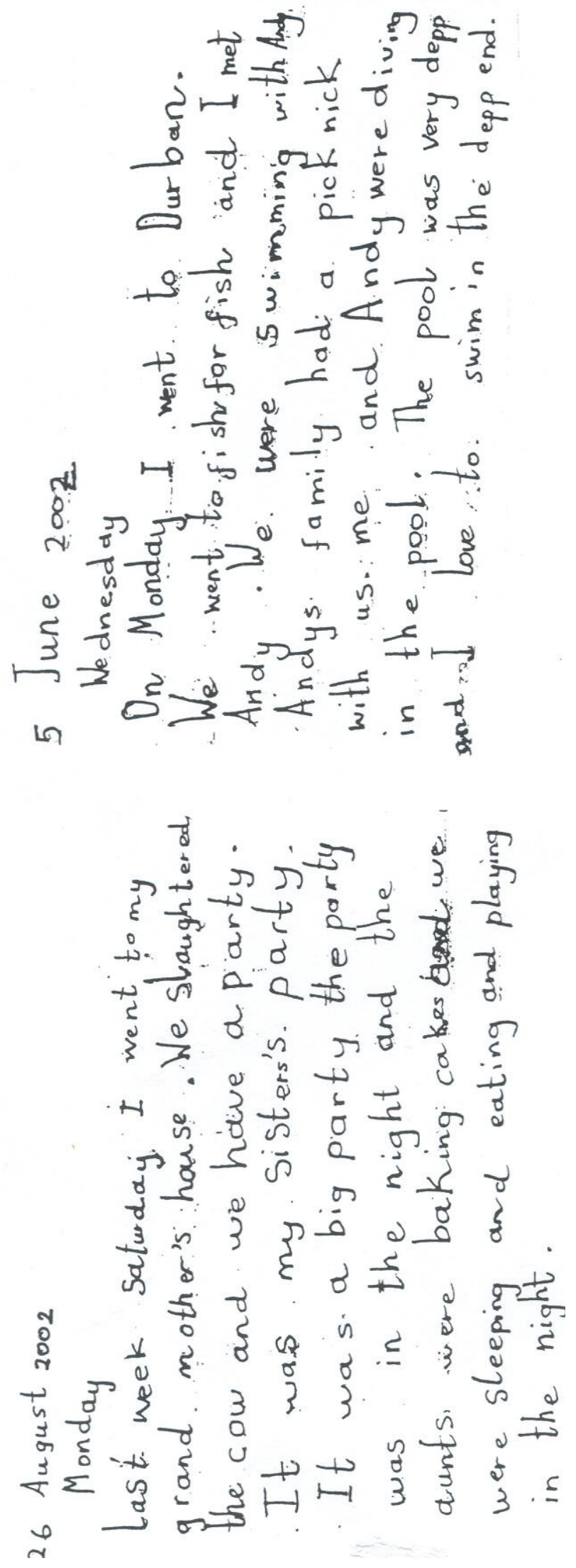


\section{PHONIC BASKETS}

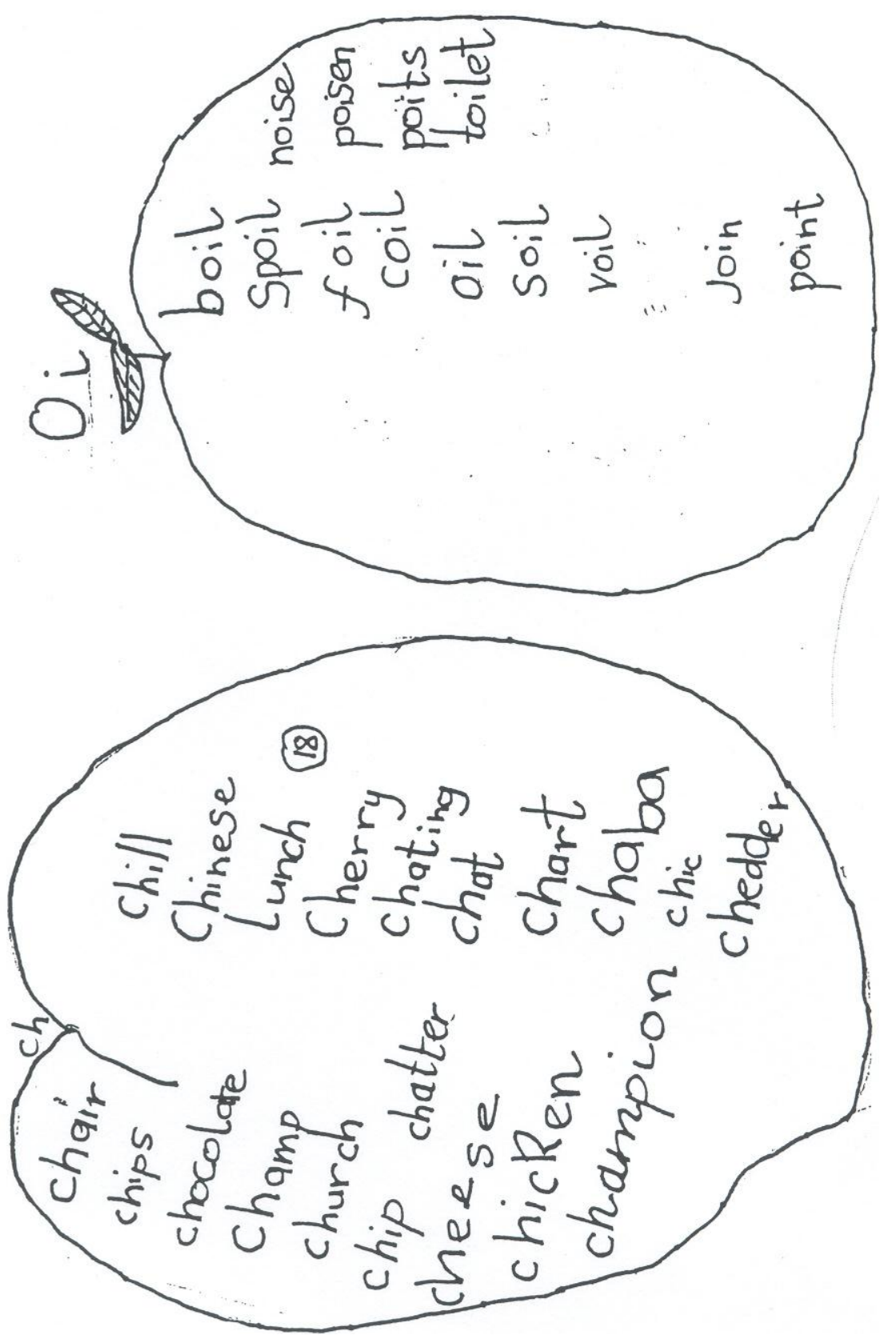

